\title{
Um registo de contabilidade medieval do Mosteiro de S. Jorge de Coimbra (1257-1259)
}

Saul António Gomes

\section{(2) OpenEdition}

\section{Journals}

\section{Edição electrónica}

URL: http://journals.openedition.org/medievalista/118

DOI: $10.4000 /$ medievalista. 118

ISSN: 1646-740X

\section{Editora}

Instituto de Estudos Medievais - FCSH-UNL

\section{Refêrencia eletrónica}

Saul António Gomes, « Um registo de contabilidade medieval do Mosteiro de S. Jorge de Coimbra (1257-1259) », Medievalista [Online], 10 | 2011, posto online no dia 02 dezembro 2013, consultado no dia 22 abril 2019. URL : http://journals.openedition.org/medievalista/118 ; DOI : 10.4000/ medievalista.118

(C) IEM 
Titulo: Um registo de contabilidade medieval do Mosteiro de S. Jorge de Coimbra (1257-1259)

Autor(es): Saul António Gomes

Enquadramento Institucional: Faculdade de Letras da Universidade de Coimbra

Contacto: sagcs@fl.uc.pt

Fonte: Medievalista [Em linha]. №10, (Julho 2011). Direc. José Mattoso. Lisboa: IEM.

Disponível em: http://www2.fcsh.unl.pt/iem/medievalista/

ISSN: 1646-740X

\section{Resumo}

Neste artigo, o autor procede ao estudo e edição de uma fonte de contabilidade monástica, datável de entre 1257 e 1259, originária do Mosteiro de S. Jorge de Coimbra, da Ordem dos Cónegos Regrantes de Santo Agostinho. Depois de se tecerem algumas reflexões acerca do interesse para a medievalística portuguesa deste tipo de fontes escritas, passa-se a uma breve contextualização histórica desta comunidade de cónegos regulares e procede-se à valorização da fonte em causa, a qual se edita no final.

Palavras-chave: Contabilidade monástica; Mosteiro de S. Jorge de Coimbra; cónegos regulares

\section{Abstract}

The author examines and publishes one source of monastic accounting, written between 1257 and 1259, from de monastery of Saint Georges of Coimbra, Order of the regular canons of Saint Augustine. After some considerations about the interest of such documents to the Portuguese medieval history, the author focuses on the conventual history of the regular canons and publishes the source. 
Keywords: Monastic accounting; monastery of Saint Georges of Coimbra; regular canons

\section{Um registo de contabilidade medieval do Mosteiro de S. Jorge de Coimbra (1257-1259)}

\section{Saul António Gomes}

Para o medievalista, em especial se português, não há fontes documentais secundárias. Todos os actos diplomáticos, públicos ou privados, cartas solenes ou notícias avulsas, conservados integral ou fragmentariamente, disponibilizados em forma avulsa ou em livro de registo ou cartulário, autênticos e mesmo falsos, são portadores de uma informação invariavelmente relevante ${ }^{1}$.

A produção documental no Portugal medieval multiplicou-se permanentemente. O estabelecimento de modo organizado de oficinas ou cartórios notariais, por iniciativa régia, posto que não exclusiva, porquanto devemos valorizar as redes de produção documental suportadas pelos poderes e quadros redactoriais eclesiásticos e nobiliárquicos, sobretudo a partir de começos de Duzentos, veio potenciar o aumento da escala de produção gráfica em todo o território ${ }^{2}$.

\footnotetext{
${ }^{1}$ Não é objectivo deste texto discutir a natureza, a génese e as tipologias das fontes da história medieval. Essa discussão, como se sabe, é recorrente. Para um estado da questão, nesta matéria, vd. MATTOSO, José - A escrita da História. Teoria e métodos. Lisboa: Estampa, 1988; GUYOTJEANNIN, Olivier - Les sources de l'histoire médiévale. Paris: Librairie Générale Française, 1998; ROSA, Maria de Lurdes "Problemáticas históricas e arquivísticas actuais para o estudo dos arquivos de família portugueses (Épocas Medieval e Moderna)". Revista de História da Sociedade e da Cultura, Coimbra. Centro de História da Sociedade e da Cultura. 9 (2009), p. 9-42: 13-14.

${ }^{2}$ NOGUEIRA, Bernardo de Sá - Tabelionado e instrumento público em Portugal. Génese e implantação (1212-1279). Lisboa: INCM, 2008; GOMES, S. A. - "O notariado medieval português. Algumas notas de investigação". Humanitas. Coimbra. Instituto de Estudos Clássicos da Faculdade de Letras da Universidade de Coimbra. LII (2000), p. 2412-286; IDEM - "Percepções em torno da história do
} 
E porque a conservação do documento escrito, em pergaminho ou em papel, preocupava o português medieval, assiste-se consequentemente à afirmação de arquivos, modestos ou de maior expressão, tanto dentro como fora das cidades. Valorizaram-se, primeiramente, mosteiros e catedrais como lugares de guarda de documentação. Tanto o rei como a nobreza e, por maioria de razão, o clero, sobretudo o secular, e até alguns municípios, encontraram nesses locais sítios e garantias de segurança para neles depositarem os documentos que acautelavam os seus direitos, heranças, privilégios, vontades testamentárias e interesses negociais ${ }^{3}$.

Os reis de Portugal, contudo, nunca deixaram de ter arquivo palatino. A transferência de uma parte da documentação para a custódia de arquivos externos, geralmente diplomas de maior importância como sucedia com testamentos reais ou tratados e acordos internacionais ou mesmo de alcance meramente interno, nos originais simples ou duplicados senão em cópias autênticas, como aconteceu com os Mosteiros de Santa Cruz de Coimbra e de Alcobaça ${ }^{4}$, não anulava a lógica e a racionalidade da existência do arquivo real em que documentos da chancelaria, enquanto instância produtora dos actos de governação pública, assim como das escrivaninhas particulares, precavendo o

tabelionado medieval português". Revista de História da Sociedade e da Cultura. Coimbra. Centro de História da Sociedade e da Cultura da Universidade de Coimbra. 5 (2005), p. 81-100.

3 Sobre esta temática, nomeadamente pela informação reunida a propósito dos arquivos monásticos portugueses, consulte-se, para além dos estudos que vão referidos na próxima nota, ROSA, Maria de Lurdes - "Problemáticas históricas e arquivísticas actuais para o estudo dos arquivos de famílias portuguesas. (Épocas Medieval e Moderna)". Cit., p. 9-42; SANTOS, Maria José Azevedo - "Remarques sur les conditions de conservation des actes et des livres au Portugal (XIIe-XVe siècles). Scriptorium, T. L (1966-2), p. 397-406.

${ }^{4}$ GOMES, S. A. GOMES - In limine conscriptionis. Documentos, chancelaria e cultura no Mosteiro de Santa Cruz de Coimbra. Séculos XII a XIV. Coimbra: Palimage, 2007, p. 241 e seguintes; IDEM “'DONATIONES CVSTODIANTVR: DONATIONES SERVENTVR' Da memória e praxis arquivística do Mosteiro de Santa Maria de Alcobaça em tempos medievais". Humanitas. Instituto de Estudos Clássicos da Faculdade de Letras da Universidade de Coimbra. 57 (2005), Coimbra, p. 245-269; IDEM "O "Inventário das Escrituras" do Convento de S. Francisco de Santarém de [1411]. Observações breves acerca da praxis arquivística medieval portuguesa". Revista de História da Sociedade e da Cultura. Coimbra. Centro de História da Sociedade e da Cultura da Universidade de Coimbra. 3, (2003 [2004]), p. 263-292. Para as catedrais diocesanas enquanto núcleos de produção e preservação de escrita veja-se Maria CUNHA, Cristina de Almeida - A Chancelaria Arquiepiscopal de Braga (1071-1244). Porto: Faculdade de Letras da Universidade do Porto, 1998; MORUJÃO, Maria do Rosário Barbosa - A Sé de Coimbra: a Instituição e a Chancelaria (1080-1318). Coimbra: Faculdade de Letras da Universidade de Coimbra, 2005; SILVA, Maria João Oliveira e - Scriptores et notatores. A produção documental da Sé do Porto (1113-1247). Porto: Fio da Palavra, 2008.

Medievalista online № $10 \mid$ Julho - Dezembro 2011 @ IEM - Instituto de Estudos Medievais 3 
exercício do deve e haver doméstico da cúria, se multiplicavam, interseccionavam tantas vezes e acumulavam ${ }^{5}$.

A administração económica foi desde cedo, na longa cronologia da humanidade, uma das esferas civilizacionais que mais impulsionou as obrigações da escrita e da sua conservação ${ }^{6}$. Os registos fiscais e administrativos, na esfera das monarquias ocidentais, no domínio eclesiástico como no de senhorios particulares ou mesmo dos institutos municipais, sem esquecer os assentos privados de prestamistas e mercadores, cresceram e multiplicaram-se nos séculos medievos ${ }^{7}$.

Em Portugal, o exercício dessa contabilidade verifica-se muito bem ao nível da fiscalidade eclesiástica ${ }^{8}$ e das suas confluências na área dos interesses pertinentes ao padroado régio ${ }^{9}$, como se estendeu ao controle dos serviços burocráticos, caso do

\footnotetext{
${ }^{5}$ A história do arquivo régio português, em tempos medievais, carece, ainda, de um estudo actualizado e sistemático. Vd. BAIÃO, António e AZEVEDO, PEDRO DE - O Arquivo da Torre do Tombo, sua história, corpos que o compõem e organização, Lisboa, 1905 [edição facsimilada, Lisboa, ANTT, 1989]; ALBUQUERQUE, Martim de - A Torre do Tombo e os seus tesouros. Lisboa: Inapa, 1990; VILAR, M. Hermínia - "Do arquivo ao registo: o percurso de uma memória no reinado de Afonso II". Penélope. Revista de História e Ciências Sociais. Lisboa. No 30/31 (2007), p. 19-50.

${ }^{6}$ GOODY, J. - A lógica da escrita e a organização das sociedades. Lisboa: Ed. 70, 1987; CLANCHY, M. T. - From Memory to Written Record: England, 1066-1307. Oxford: Blackwell, 1993.

${ }^{7}$ Vd. BISSON, Thomas N. - Fiscal accounts of Catalonia under the Early Count-Kings (1151-1213). Vol. 1. Introduction. Berkeley-Los Angeles-London: Univerity of California Press, 1984, p. 23 e seguintes.

${ }^{8}$ Cf., por exemplo, COSTA, Avelino de Jesus da - O Bispo D. Pedro e a organização da Diocese de Braga. 2 vols.. $2^{a}$ edição. Braga2000; MARQUES, José - "O censual do Cabido de Tui para o arcediagado da terra da Vinha - 1321". In Relações entre Portugal e Castela nos finais da Idade Média. Lisboa: Fund. Calouste Gulbenkian e FCT, 1994, p. 65-104; SOALHEIRO, João - "Censual da diocese de Coimbra - século XIV (ANTT: MCO, Ordem de Cristo/Convento de Tomar, liv. 264)". Revista de História da Sociedade e da Cultura. Coimbra. Centro de História da Sociedade e da Cultura da Universidade de Coimbra., 6 (2006), pp. 51-90; MARTIN MARTIN, Luis - "El poblamiento de Portugal según 'Collectoriae' vaticanas del siglo XIV: diócesis de Lisboa y Coimbra". Revista da Faculdade de Letras. História. Porto. Faculdade de Letras da Universidade do Porto., 13, 2a série, (1996), p. 123-148.

${ }_{9}^{9}$ Vd. BOISSELLIER, Stephane - Registres fiscaux et administratifs de benefices ecclésiastiques du royaume portugais, XIII-XIVe siècles (edition et présentation). Contribution a l'étude du phenomène administratif, [2009], (no prelo). IDEM, "Les rapport entre prélèvement fiscal et mécanismes économiques: leurs représentations dans les Cortes au Portugal dans la première moitié du XIVe siècle". In La fiscalità nell'economia europea. Secc. XIII-XVIII. Atti XXXIX Settimana di Studi, (Ed. Simonetta CAVACIOCCHI). Florença,2008, p. 1083-1103; NOGUEIRA, Bernardo de Sá - "A organização do padroado régio durante o reinado de D. Dinis. Lista das apresentações (1279-1321)". In Arqueologia do Estado. $1^{a}$ S Jornadas sobre formas de organização e exercício dos poderes na Europa do Sul. Séculos XIII-XVIII. Comunicações. Vol. 1. Lisboa: Faculdade de Letras da Universidade de Lisboa. 1988, p. 421445; KRUS, Luís - "A Consolidação de Portugal”. In Memória de Portugal. O Milénio Português (Dir. Roberto Carneiro; Coord. Artur Teodoro de Matos). Rio de Mouro: Círculo de Leitores. 2001, p. 107163, maxime 126-127 e 142-143; VILAR, Hermínia, D. Afonso II. Um rei sem tempo. Rio de Mouro: Círculo de Leitores. 2005, p. 150 e seguintes; IDEM - "Do arquivo ao registo: o percurso de uma
}

Medievalista online $\mathrm{N}^{0} 10 \mid$ Julho - Dezembro 2011 ๑ IEM - Instituto de Estudos Medievais 4 
tabelionado e das respectivas receitas geradas por cada cartório notarial logo nos finais de Duzentos ${ }^{10}$. É um fenómeno que se atesta, como se sabe, desde o reinado de D. Afonso II, vindo a acentuar-se particular e reiteradamente no século XIV ${ }^{11}$.

Não é, assim sendo, uma novidade que nos mosteiros medievais se encontrem, por norma, exemplos de boa gestão económica tanto ao nível do património base dessas instituições, dos seus domínios e coutos, bens e propriedades, directa ou indirectamente explorados e com proventos expressos em foros e rendas, como ainda de outros proventos avulsos, esmolas ou benefícios caritativos, expressos em géneros ou em dinheiro, provenientes de fiéis e benfeitores piedosos que lhes solicitavam ofícios e serviços litúrgicos de significado sobretudo espiritual ${ }^{12}$.

O deve e haver das contabilidades monásticas detecta-se bem cedo no Ocidente $^{13}$. Georges Duby pôde estudar, de modo assaz preciso, os gastos e rendas da Abadia de Cluny entre 1080 e $1155^{14}$. Outros exercícios foram positivamente logrados para a situação portuguesa como se demonstra à saciedade nos estudos dedicados por Iria Gonçalves, ao Mosteiro de Alcobaça ${ }^{15}$, no de Maria Helena Coelho em relação à Granja

memória no reinado de Afonso II". Penélope. Revista de História e Ciências Sociais. Lisboa. N ${ }^{o}$ 30/31 (2007), p. 19-50.

${ }^{10}$ MARQUES, A. H. de Oliveira - "A população portuguesa nos fins do século XIII". In Ensaios de história medieval portuguesa. $2^{a}$ edição. Lisboa: Ed. Veja. 1980, p. 51-92.

${ }^{11} \mathrm{Vd}$. BOISSELLIER, Stephane - Registres fiscaux et administratifs de benefices ecclésiastiques du royaume portugais, XIII-XIVe siècles... Cit.; FARELO, Mário - "Bibliografia sobre fiscalidade eclesiástica", divulgado on line em http://www.fcsh.unl.pt/iem/disponibilizar-biblio-iem-htm, 2007. [Consult. 16 Jun. 2010].

${ }^{12}$ Esta divisão binária nas economias monásticas tem sido afirmada, tanto para o monaquismo de tradição beneditina e canonical, quanto para o mendicante, por diversos autores. Vd. POWER, Eileen - "Medieval Monastic Finance". The Economic History Review. Vol. 7, № 1 (Nov., 1936), p. 87-92; ROSA, Maria de Lurdes - "Problemáticas históricas e arquivísticas...", p. 13, nota 5. A importância das doações e esmolas nas economias de conventos mendicantes ficam bem evidenciados na obra de BERTRAND, Paul Commerce avec dame Pauvreté. Structures et fonctions des couvents mediants à Liège (XIIIe-XIVe s.). Liège: Université de Liège. 2004, p. 181 e seguintes.

13 Cf. SNAPE, R. - English monastic finances in the Later Middle Ages. Cambridge, 1926; A, VAUCHEZ, A. E CABY, Cécile(Dir.) - L'Histoire des moines, chanoines et religieux au Moyen Âge. Guide de recherche et documents. Turnhout: Brepols, 2003, p. 109 e seguintes; RACINET, Philippe Moines et monastères en Occident au Moyen Âge en hommage à Dom Jacques Dubois. Paris: Ed. Ellipses, 2007, p. 196-198.

${ }^{14}$ DUBY, G. - "Le budget de l'abbaye de Cluny entre 1080 et 1155 . Économie domaniale et économie monétaire". In Hommes et structures du moyen âge. Recueil d'articles. Paris-La Haye: École des Hautes Études en Sciences Sociales e Paris \& Mouton Éditeurs, 1984, p. 61-82.

15 GONÇALVES, Iria - "Custos de montagem de uma exploração agrícola medieval". In Estudos de História de Portugal. Séculos X-XV. Homenagem a A. H. de Oliveira Marques. Lisboa: Editorial Estampa, 1982, p. 255-270; IDEM - O património do Mosteiro de Alcobaça. Lisboa: Universidade Nova de Lisboa, 1989. 
de Alvorge, do Mosteiro de Santa Cruz de Coimbra ${ }^{16}$ ou no de Luís Carlos Amaral sobre o Mosteiro de São Salvador de Grijó ${ }^{17}$. E os exemplos poderiam alargar-se ao universo municipal ou mesmo do erário público régio nacional ${ }^{18}$ ou fora do país mas debaixo de uma gestão portuguesa ${ }^{19}$.

2 - A fundação do Mosteiro de S. Jorge, situado um pouco a nascente da cidade de Coimbra, segundo as crónicas modernas dos cónegos regrantes de Santo Agostinho, dever-se-ia ao Conde D. Sesnando, o celebrado governador moçárabe de Coimbra. Caçava o Conde veados e porcos monteses, pelas imediações da mata de Mirleus, quando o cavalo, desenfreado, corria para um perigoso precipício. E reza, ainda, essa lenda encantada cujos tópicos narrativos se reencontrarão coincidentemente na mais popular lenda de D. Fuas Roupinho, relativa à praia estremenha da Nazaré, que o Conde, na iminência do desastre, invocou S. Jorge e logo o animal estancou milagrosamente, as patas no ar, permitindo ao cavaleiro apear-se e salvar-se.

Em memória do maravilhoso acontecimento, D. Sesnando teria mandado levantar nesse local, em 1080, uma ermida dedicada a S. Jorge, fazendo-a mudar, quatro anos depois, para outro lugar, justamente aquele onde o mosteiro, segundo os cronistas crúzios, viria a ser edificado. O padroado desta igreja terá transitado de D. Sesnando para D. Elvira

\footnotetext{
${ }^{16}$ COELHO, Maria Helena da Cruz - "O senhorio crúzio do Alvorge na Centúria de Trezentos". In Homens, Espaços e Poderes. Séculos XI-XVI. II — O Domínio Senhorial. Lisboa: Livros Horizonte, 1991, p. 31-92. Assinale-se que, nesta mesma obra, a Autora apresenta estudos de exercício de contabilidade monástica crúzia, e mesmo cisterciense, relativamente ao Mosteiro de S. João de Tarouca, mas já para o século XVI., cronologia em que o panorama medieval, neste género de fontes, se altera substancialmente. ${ }^{17}$ AMARAL, Luís Carlos - São Salvador de Grijó na segunda metade do Século XIV. Estudo de gestão agrária. Lisboa: Edições Cosmos, 1994, p. 145-166.

${ }^{18}$ Vd. BOTÃO, Maria de Fátima - "As fontes contabilísticas na retratação de um espaço em movimento". In Paisagens Rurais e Urbanas - Fontes, Metodologias, Problemáticas. Actas das Primeiras Jornadas. Lisboa: Centro de Estudos Históricos da Universidade Nova de Lisboa, 2005, p. 123-131.

${ }^{19}$ FONSECA, Luís Adão da - "As finanças reais no governo do Condestável Pedro de Portugal em Barcelona (1464-1466)". Separata de El Món Urbà a la Corona d'Aragó del 1137 als Decrets de Nova Planta. XVII Congrés d'Història de la Corona d'Aragó. Barcelona-Lleida, 7-12 de setembre del 2000, p. 1-5; HENRIQUES, António Castro - State Finance, War and Redistribution in Portugal, 1249-1527, York, University of York, 2008.
} 
Sesnandes, sua filha e casada com Martinho Moniz, os quais, por sua vez, o terão transmitido a um seu sobrinho, Salvador Guimariz, diácono ${ }^{20}$.

Data de Julho de 1146, na verdade, o compromisso feito por "Saluatorio diacono Guimariz" com os "hominibus quibuscumque religiosis mecum conversari uolentibus siue successoribus eorum de illa heremita ecclesie sancti Georgii martyris que est constructa in finibus Colimbrie supra ripam fluminis Mondeci cum turri que dicitur de Canardo (?)." Comprometia-se Salvador Guimariz, diante de D. João, bispo “Dei gratia electus", e subscritor do acto, a partilhar com os seus companheiros o património que para esta fundação se estabelecia, a fim de que tudo fosse partilhado em comum: "sed sicut nobis ibi omnia in Christo communia". Afirmava-se, também, o fito espiritual da fundação: "Et hoc facio pro salute animee mee et illorum qui mecum in eo loco caste et pie uiuendo regulariter Deo seruire studuerint."21

O envolvimento do bispo eleito de Coimbra, D. João Anaia, deixa transparecer a dependência da fundação deste cenóbio do poder episcopal coimbrão. Que a fundação correspondia a uma canónica regrante colhe-se, de imediato, da doação de bens em Vila Franca (Coimbra), lavrada por Flamula Garsia, em Agosto desse mesmo ano de 1146, aos "canonicis sancti Georgii", mencionando-se os nomes dos presbíteros João, Domingos, Lourenço, João (II) e Salvador e outros "uestris omnibus sociis",22.

A este mosteiro ligaram-se, por especial devoção, os monarcas da dinastia afonsina. D. Sancho I e D. Dulce, sua mulher, entregaram, em 1191, a dízima da herdade régia de

\footnotetext{
${ }^{20}$ Sobre este Mosteiro, consulte-se SANTA MARIA, D. Nicolau de - Chronica da Ordem dos Conegos Regrantes do Patriarcha S. Agostinho. Parte II. Lisboa: Oficina de João da Costa, 1668, p. 151-158; MÁRTIRES, D. Timóteo dos - "Mosteiro de São Jorge de junto a Coimbra. Sua fundação, união, refformação e huns e outros priores", O Instituto, No 121 (1959), p. 1-20: 1-3.; DINIS, Maria José - O Mosteiro de S. Jorge. Subsídios para a sua história nos séculos XII e XIII, [Dissertação de Licenciatura, policopiada]. Coimbra: Faculdade de Letras da Universidade de Coimbra, 1961; FERNANDES, Aires Gomes - "As relações entre a Coroa e o Mosteiro de S. Jorge de Coimbra em tempos medievos", Lusitania Sacra, 17 (2005), p. 331-376; SOUSA, Bernardo Vasconcelos e (Dir.) - Ordens Religiosas em Portugal das origens a Trento. Guia Histórico. Lisboa: Livros Horizonte, 2006, p. 185.

${ }^{21}$ Direcção Geral de Arquivos - Torre do Tombo (Doravante citado por TT) — Mosteiro de S. Jorge de Coimbra, $\mathbf{M}^{\text {o }}$ 1, Doc. 36. (Na carta de doação de Maria Muzariz e de seus filhos aos homens que, em S. Jorge, quisessem levar vida regular, datada também de Julho de 1146, refere-se "turris Kaniardi". (TT Mosteiro de S. Jorge de Coimbra, $\mathrm{M}^{\mathrm{o}}$ 1, Doc. 35)).

${ }^{22}$ TT - Mosteiro de S. Jorge de Coimbra, $\mathrm{M}^{\mathbf{0}}$ 1, Doc. 37.
} 
Façalamim aos cónegos, sendo prior-mor D. Pedro Vicente ${ }^{23}$, em reconhecimento da intervenção do santo mártir na protecção ao infante D. Afonso, futuro rei, quando este se mostrava, pouco depois do nascimento, ainda "muito enfermozinho e tolhido" 24 .

O apoio do rei D. Sancho I ao Mosteiro de S. Jorge foi reiterado, em 1194, a propósito da cedência que o prior-mor, D. Gonçalo Martins, e demais cónegos fizeram, "in nostra presentia", em benefício do chanceler régio D. Julião, de certo caneiro de água necessário aos moinhos que o chanceler tinha em propriedade contígua à herdade dos religiosos agostinhos. Subscreveram o acto o prior-mor, o prior claustral, o prepósito, os dois chantres e treze outros cónegos, num total de 18 cónegos professos ${ }^{25}$. Também no ano seguinte, a família real, com o Infante D. Afonso à cabeça, em conjunto com D. Gonçalo Martins, prior-mor do Mosteiro de S. Jorge, todo o seu convento e, ainda, com Fr. João, da Albergaria de Poiares, promulgam carta de foral, segundo o costume de Évora, aos povoadores de S. Vicente da Beira ${ }^{26}$. No seu segundo testamento, lavrado em 1210, D. Sancho I deixa a S. Jorge 500 morabitinos $^{27}$.

Em 1216, D. Afonso II toma debaixo da sua real protecção este cenóbio para, pouco depois, em 1221, o papa Honório III conceder-lhe o privilégio da isenção diocesana ${ }^{28}$. Também D. Afonso III, num acto de fé que recorda o sucedido com o seu pai, se voltou para esta canónica de Coimbra, em 1259, suplicando a intercessão de S. Jorge para que a sua filha primogénita, a Infanta D. Branca — nascida, recorde-se, do seu consórcio com D. Beatriz, e em tempo de interdito sobre o reino devido à situação de bigamia do monarca luso - , pela misericórdia divina, usufruísse de uma "vitam longuam" e para que Deus protegesse e defendesse "eam per tempora longuiora et quod dominus Ihesus

\footnotetext{
${ }^{23}$ DOCUMENTOS de D. Sancho I (1174-1211), (Ed. AZEVEDO, Rui de, COSTA, Avelino de Jesus da e PEREIRA, Marcelino Rodrigues). Coimbra: Centro de História da Universidade de Coimbra, 1979, Doc. 51, pp. 82-83.

${ }^{24}$ MÁRTIRES, D. Timóteo dos - "Mosteiro de São Jorge de junto a Coimbra. Sua fundação, união, refformação e huns e outros priores". O Instituto. Coimbra. Instituto de Coimbra. No 121 (1959), p. 1-20: 1-3. (De facto, o diploma de doação da dízima de Façalamim ao Mosteiro, de 1191, citado na nota anterior, refere expressamente ser doação feita, citamos: "intuitu amoris Dei et beati Georgii martiris et filii nostri regis domni Alfonsi quem Deo et beato Gergio super altare eiusdem martiris obtulimus decimam predicte hereditatis in perpetuum habendam (...).").

${ }^{25}$ DOCUMENTOS de D. Sancho I..., Doc. 70, pp. 107-108.

${ }^{26}$ DOCUMENTOS de D. Sancho I..., Doc. 83, pp. 129-132.

${ }^{27}$ Quantia igual foi legada aos Mosteiros de S. Vicente de Fora de Lisboa, Lorvão, Salzedas e S. João de Tarouca. Vd. DOCUMENTOS de D. Sancho I..., Doc. 194, p. 298.

${ }^{28}$ MÁRTIRES, D. Timóteo dos MÁRTIRES, Op. cit., p. 3.
} 
Christus liberet me a potestate diaboli." Para mais afirmar e vincular o seu voto, o rei doou ao prior e aos cónegos deste mosteiro, a 20 de Março do dito ano, estando em Santarém, o padroado da igreja de Santa Maria de Portalegre ${ }^{29}$.

Pelo que possuía em Santarém estava o mosteiro obrigado a dar ao monarca lenha, um dia por semana, sempre que a corte régia jornadeasse naquela vila ribatejana. Obrigação de que prescindiu o Bolonhês, "verus patronus" de S. Jorge, por carta de 10 de Janeiro de 1269 , promulgada justamente em Coimbra $^{30}$.

3 - No século XIII, S. Jorge de Coimbra usufruía de um património rentável e apreciável. Por doação, compra ou escambo, este instituto regular estendeu o seu património, para além do que tinha em Coimbra, a Castelo Viegas ${ }^{31}$, Arregaça ${ }^{32}$, Taveiro $^{33}$, num aro geográfico ainda muito próximo de Coimbra, e, depois, num segundo círculo já mais distanciado, a terras como Lorvão, Penela ${ }^{34}$, Tentúgal, Montemor-o-Velho, Lavos ${ }^{35}$, Ameal e Façalamim. S. Jorge tinha, finalmente, interesses senhoriais apreciáveis em pontos bem mais longínquos como eram Arganil, Celorico [da Beira], Paços, Covilhã, S. Vicente da Beira [“de ultra serram”], Rio de Moinhos, junto a esta vila, Santarém e Portalegre ${ }^{36}$.

\footnotetext{
${ }^{29}$ TT - Mosteiro de S. Jorge de Coimbra, M 6 , Doc. 21. (Pública-forma lavrada por Salvado Domingues, tabelião público de Coimbra, a pedido de Pedro Esteves, cónego do mosteiro, em 9 de Abril de 1304, Coimbra). A doação em causa aparece, também, registada na CHANCELARIA de D. Afonso III. (Ed. VENTURA, Leontina e OLIVEIRA, António Resende de), Livro 1 - Volume 1, Coimbra, Imprensa da Universidade de Coimbra, 2006, Doc. 191, p. 214.

${ }^{30}$ CHANCELARIA de D. Afonso III, cit., Doc. 400, p. 459-460.

${ }^{31}$ TT - Mosteiro de S. Jorge de Coimbra, $\mathrm{M}^{\circ}$ 3, Doc. 10. (Doação, com data de Fevereiro de 1166, de Salvador Viegas a S. Jorge "ibique canonicis Deo seruientibus", da sua propriedade em Castelo Viegas).

${ }^{32}$ TT - Mosteiro de S. Jorge de Coimbra, $M^{\circ}$ 3, Doc. 15. (Doação de João Mendes, ao mosteiro, de metade da herdade e almoinha que tinha na Arregaça, com data de Janeiro de 1168).

${ }^{33}$ TT - Mosteiro de S. Jorge de Coimbra, Mํ 4, Doc. 5. (Doação de Ausenda Guterres e seus filhos e genros ao Mosteiro, com data de Março de 1174).

${ }^{34}$ TT - Mosteiro de S. Jorge de Coimbra, Mo 4, Docs. 29 e 30. (Escambo, datado de Novembro de 1187, entre Justa Vicente e D. Pedro Vicente, prior de S. Jorge e convento, de uma vinha com as suas cubas e moinhos e pertenças, em Penela, por outra em Alcanzi).

${ }^{35} \mathrm{TT}$ - Mosteiro de S. Jorge de Coimbra, $\mathrm{M}^{\circ}$ 6, Doc. 2. Publ.: COELHO, Maria Helena da Cruz - O Baixo Mondego nos Finais da Idade Média. (Estudo de História Rural). Vol. II. Coimbra: Faculdade de Letras, 1983, Doc. 9, p. 740.

${ }^{36}$ TT - Sé de Coimbra, $\mathbf{M}^{\circ}$ 15, Doc. 30.
} 
Num pequeno caderno de registos documentais, do primeiro terço do século XIII, que indicia um balbuciante cartulário deste mosteiro, foram lançadas cópias de diplomas, datados de entre 1167 e 1211, relativos às propriedades que o cenóbio detinha em Toxe e Alvorge (Santarém). Nele foi trasladado, ainda, o contrato, de Junho de 1238, com João Eanes Remelado, sobre a exploração da vila de S. Vicente [da Beira], que deveria render à vestiaria monástica 100 morabitinos de ouro em cada ano.

Para além disso, recolheu-se, neste caderno, uma "noticia de aniuersariis" instituídos na igreja de Santiago [de S. Vicente da Beira], um rol do dinheiro despendido por Martinho Mendes na lavoura e amanho de terras da canónica e alguns lanços das verbas percebidas, também, por Martinho Mendes “cum sociis suis”, na portagem de Coimbra, num valor que se estimava em 1500 maravedis anuais, discriminando-se, no averbamento em causa, os valores do dinheiro entrado relativamente aos dias situados entre 3 e 12 de Abril de $1224^{37}$.

Este pequeno caderno reúne, como se expôs, fontes relativas a três tipos de receitas económicas do claustro: a primeira relativa às terras e propriedades, e seus modos de exploração contratual; a segunda aos proventos dos aniversários e legados pios; a terceira, por último, alusiva ao dinheiro colectado na portagem coimbrã ${ }^{38}$ ), fechando com um rol das despesas realizadas na exploração directa de parte das terras do domínio monástico. Ele revela as preocupações que a canónica tinha com a administração do seu património, de modo a inscrever em cadernos do arquivo canonical a informação que cumpria acautelar, revelando a presença de um ecónomo (Martinho Mendes) responsável pela recolha de rendas e pela gestão pelo menos de uma parte do domínio agrário dos cónegos de S. Jorge.

Na primeira metade do século XIII, como vimos, o Mosteiro de S. Jorge de Coimbra mantinha práticas de administração que passavam pela escrita organizada. Se o "caderno de registos", atrás citado, o indicia já, o documento que aqui publicamos apresenta, para os anos económicos de 1257 e 1259, um balanço do deve e do haver desta canónica regrante.

\footnotetext{
${ }^{37}$ TT - Mosteiro de S. Jorge de Coimbra, $\mathrm{M}^{\mathbf{0}}$ 3, Doc. 12.

${ }^{38} \mathrm{Em}$ 1404, ainda o Mosteiro cobrava rendas na portagem coimbrã. Vd. COELHO, Maria Helena da Cruz - O Baixo Mondego nos Finais da Idade Média..., Vol. II. Cit., Doc. 52, pp. 807-808.
} 
Poderemos classificá-lo como registo de contabilidade monástica, numa tipologia documental rara, sobretudo para essa época, nos nossos arquivos, mas que vem demonstrar, uma vez mais, a proliferação dos mecanismos de uma escrita contabilística no Portugal ducentista. Nele percorre-se longamente o património monástico dominial arrolando-se rendas e proventos cujas entradas se faziam pelas ovenças, respectivamente, da enfermaria, da vestiaria e da correaria. O hospital monástico e a "pitançaria" são referidos muito de passagem como tendo rendimentos próprios. Individualiza-se, ainda, uma boa parte, senão todos, os proventos exclusivos do priormor. No final do texto aparece um breve rol com as dívidas ${ }^{39}$.

Devemos atender, no entanto, que este registo de contabilidade monástica é, simultaneamente, um documento que arrola, inventaria e delimita o exercício dos poderes no interior desta canónica coimbrã. Ao identificar os bens e respectivas rendas das ovenças como a enfermaria, a vestiaria, a correaria, delimita-as nas garantias das suas fontes de receita, ao mesmo tempo que arrola o que pertence à mesa do prior-mor.

Neste sentido, o registo em causa é um acto que resulta, como referimos, de um exercício de reconhecimento e afirmação dos poderes endógenos de uma canónica agostiniana, de estatuto e protecção reais, no Portugal de meados do século XIII, garantindo os direitos patrimoniais da comunidade conventual e expondo os que eram pertença do prelado. E nestes, aliás, pressente-se uma certa denuncia de incapacidade de gestão e até de abuso de exercício de autoridade, por parte do prior-mor, demonstrável nas rendas que se não cobravam ou na apropriação, pelo prelado, de rendimentos que eram das ovenças.

\footnotetext{
${ }^{39}$ Esta organização institucional estruturada por ovenças ou unidades de gestão endógena era vulgar nos mosteiros de cónegos regrantes de Santo Agostinho. Encontramo-lo muito evidenciado em Santa Cruz de Coimbra, em S. Vicente de Fora, em Grijó ou em S. Pedro de Folques, junto a Arganil. Vd. MARTINS, Armando Alberto - O Mosteiro de Santa Cruz de Coimbra na Idade Média. Lisboa: Centro de História da Universidade de Lisboa, 2003, p. 750-758; AMARAL, Luís Carlos - S. Salvador de Grijó..., cit., p. 149152; SILVA, Carlos Guardado da - O Mosteiro de S. Vicente de Fora. A comunidade regrante e o património rural (Séculos XII-XIII). Lisboa: Ed. Colibri, 2002, p. 71-74; GOMES, S. A. - In limine conscriptionis..., cit., p. 171-172; IDEM - "A Chancelaria do Mosteiro de S. Vicente de Fora de Lisboa nos Séculos XII e XIII: Subsídio para o seu Conhecimento". In Svmmvs Philologvs Necnon Verborum Imperator. Colectânea de Estudos em Homenagem ao Académico de Mérito, Professor Dr. José Pedro Machado no seu $90^{\circ}$ Aniversário. Lisboa: Academia Portuguesa da História, 2004, p. 163-213; IDEM - “ 'Trado me ipsum...' - Registos medievais de traditio monástica entre os Cónegos Regrantes de Santo Agostinho em Portugal". In Estudos em Homenagem ao Professor Doutor José Marques. Vol. 4. Porto: Faculdade de Letras da Universidade do Porto, 2006, p. 329-348; IDEM - Um Mosteiro de Cónegos Regrantes em Tempos Medievais: S. Pedro de Folques (Arganil) (no prelo [2008]).
} 
Não significa esta leitura, contudo, que este tipo de diplomas, de inventário e contabilidade, apenas emergissem em situações de crise ou de conflito no seio das comunidades monásticas que nos interessam. Essas situações, naturalmente, poderiam contextualizar a redacção deste tipo de actos, mas importa sublinhar a capacidade técnica da sua concretização. E é a este nível mais profundo, o da inteligência redactorial em que a palavra e o número se associam no discurso financeiro, que importa situar o documento em causa. Não como uma excepção ao serviço da demonstração de poderes, mas como peça que resulta de um saber e de uma prática contabilística natural num senhorio monástico.

De uma leitura global deste registo contabilístico, verificamos que se intersectam neste claustro dois tipos de economia. Pesavam os pagamentos em géneros alimentares, em animais e até em escravos sarracenos. Mas a linha dominante neste micro-universo monástico é a da economia monetária. Procura-se avaliar todos os proventos em moeda, valorizando-se vendas e rendas expressas em dinheiro. Ainda que nem sempre isso aconteça, como sucede com a verba relativa aos três moios de centeio e um sarraceno recebidos, em 1257, pelo prior da enfermaria. Trigo, centeio, milho mourisco e milho, sem mais, tinham boa recepção no mercado urbano, valendo cada alqueire de trigo, nesse ano, quatro soldos. Como se vendiam bem, cremos, "panos", decerto lanifícios para cuja manuifactura não faltava matéria-prima nos celeiros do Mosteiro. Os panos vendidos pelo prior a Vicente Serrão, por exemplo, tinham valido a soma de sete libras.

A venda da herdade de S. Simão de "Penellola" gerara uma receita de 80 libras. E, de Lorvão, recebia-se uma renda de 40 libras, dois terços das quais eram repartidos pela vestiaria e pela correaria. O Mosteiro era senhorio de muitas cabeças de gado miúdo e de apreciáveis boiadas. Um dos seus ovelheiros, Vicente, entregou aos cónegos 80 ovelhas e um asno, e D. Pedro, irmão de D. Sebastião, oito vacas, um boi e mais de 40 ovelhas; de um outro ovelheiro, Durando, recebeu-se 60 ovelhas e 13 libras em dinheiro. Pedro Gonçalves de "Paliom", por seu turno, pagou oito cabeças de vacas, entre grandes e pequenas, 10 cabras, três asnos, um boi e um bom "zorame et sagiam".

O hospital monástico entregara, em dois anos, a lã de 300 ovelhas, acentuando a relevância na economia deste mosteiro do gado lanígero e o peso que os produtos dele derivados, sobretudo a lã, como vemos, atingia. 
Entre os rendimentos variáveis situavam-se os 10 moios de milho que o rei doara para pitança aos frades, mas "nihil inde habuerunt". Da pitançaria de Santarém saíam 30 e mais libras de pão. A "pitançaria" tinha três e mais libras anuais, em Albarrol, pagas por Fernando Martins de Penela. A ferragem da almoinha da correaria rendia sete libras e os moinhos 4,5 libras por dia. Da vila de S. Vicente de "ultra serram" deveriam receber-se 200 libras anualmente, mas elas estavam por pagar desde 1257. Casos havia, ainda, de rendas subestimadas como sucedia com os cinco casais do Ameal, entregues pelo priormor, pelo prazo de um quadriénio, a Pedro Salvado, por 100 libras, se bem que valessem 200 .

Da vinha da correaria recebia-se todo o vinho, mas a ausência de cavadura da mesma pelo caseiro, quando já floresciam as cepas, prejudicara a vindima. Quem fosse o responsável pela manutenção dessa vinha, não se indica. Cita-se, junto dessa parcela, que o mouro Mafomede entregara 57 libras à correaria, se bem entendemos. Seria este mouro o arrendatário da vinha em causa?

O Mosteiro tinha alguns olivais, poucos, rendendo, os que trazia D. Bento, "fibularius", cinco libras. A mesa prioral auferia, como seria de esperar, da maior parte das rendas monásticas e, vezes havia, ainda, que o prior-mor se socorria dos proventos das ovenças da comunidade para dar satisfação a despesas que entendia convenientes quando deu algumas bestas, da correaria, a João Pais da Covilhã e a Pedro Peres "Lanyoso" ou dela recebeu sete carneiros para gastos.

Do "ano isto proximo preterito", ou seja, 1258, não estava ainda apurado quanto o enfermeiro e o correeiro monásticos haviam entregado ao prior-mor. Sabe-se, no entanto, que o prelado recebeu os leitos e as cobertas de sete frades falecidos nesse período.

Não se apontam valores para o rendimento dos bens de Portalegre e da Covilhã, talvez por dificuldades de se levar a bom cabo a respectiva cobrança. Dos quatro casais de Celorico, por seu lado, havia já dois anos que nada se cobrava.

O claustro contraiu dívidas, nesses anos, para compra de cereal. A Pedro Manso, de Façalamim, seis moios de trigo; ao cónego Martinho Pais, de Coimbra, dois moios de 
trigo e outros dois de milho; ao Bispo de Coimbra, dois moios de milho e dois quarteiros de trigo; ao mercador Pedro Salvado, um moio de trigo e a Martinho Moniz, também mercador, seis quarteiros do mesmo cereal; ao carpinteiro Martinho Pais, da paróquia de S. Bartolomeu, foi comprado um moio de milho.

Não se explica cabalmente a razão desta necessidade de compra de cereais, pelos cónegos de S. Jorge, no mercado coimbrão. Dificilmente nos parece de admitir a hipótese de se atravessar, nesses anos, uma época de crise agrícola ou mesmo de escassez geral de cereais. Tanto assim não era, aliás, que o mosteiro encontrou no mercado local coimbrão o cereal de que necessitou.

A necessidade de trigo e de milho talvez se possa explicar por razões que se prendessem com o sustento da comunidade e um provável défice de entradas de trigo e de milho nos celeiros conventuais - lembremos que os 10 moios de milho doados pelo rei aos cónegos também não estavam a ser pagos —, talvez, ainda, por necessidade de grão para novas sementeiras, ou, sobremodo, por deficiente administração e recolha das rendas da instituição. Rendas em que, como anotámos, predominavam mais os pagamentos em moeda do que verdadeiramente em géneros, ainda que estes existissem.

A hipótese da falta de cereal nos celeiros do convento, contudo, poderá derivar de episódica deficiente gestão económica deste claustro. O próprio documento que seguimos refere que havia dois anos que o cabido monástico não se celebrava, sintoma de que algo não estava a decorrer regularmente neste claustro. Por 1258, aliás, parece ter assumido a cadeira prelatícia do mosteiro D. Gomes Lopes, substituindo D. Vicente Eanes, prior-mor desde $1247^{40}$.

4 - S. Jorge de Coimbra conheceu tempos de prosperidade e outros de crise interna. No ano de 1192, o claustro acolhia 26 cónegos e exercia jurisdição sobre a comunidade feminina de cónegas agostinhas da Santa Ana, para a qual se apontam, nessa data, nove professas $^{41}$. Dados que indiciam um ciclo de vitalidade na história desta comunidade

\footnotetext{
${ }^{40}$ MÁRTIRES, D. Timóteo dos - Op. cit., p. 5.

${ }^{41}$ SOUSA, Bernardo Vasconcelos e (Dir.) - Ordens Religiosas em Portugal..., cit., p. 185.
} 
regular. Mas o documento que motiva este artigo, por seu lado, revela sintomas de crise dentro da instituição nos finais da década de $1250^{42}$.

Sabemos, também, que em 21 de Junho de 1264, D. Egas, bispo de Coimbra, se apresentou no mosteiro para fazer visitação "tam in capite quam in membris", recebendo em mãos a renúncia de Gomes Lopes, prior e demais convento, "uolentes uitare dampna ipsius Monasterii", a fim de que ali se mantivesse a paz e a concórdia ${ }^{43}$.

Que discórdias e rivalidades então dividiam os religiosos de S. Jorge não sabemos. Mas elas foram recorrentes. Numa sentença proferida por Pascásio Nunes, arcediago e vigário da Diocese de Coimbra, em 29 de Julho de 1287, dirimiu-se a questão que opunha o prior-mor e o convento, representados pelo seu procurador e cónego regular, Pedro Peres, a João Salvadores, também ele cónego professo deste mosteiro.

O conflito entre estas partes respeitava aos direitos de posse sobre umas casas, situadas no "vico de couis Colimbrie", que tinham sido do pai de João Salvadores e de que era herdeiro. Alegava o procurador dos cónegos, no entanto, que tais casas deveriam pertencer de direito à instituição monástica, pois que o dito João Salvadores era cónego e professo desse cenóbio e "de iure et de consutudine regule sui ordinis nichil proprium deberet habere." Reconheceu-se a S. Jorge, de facto, o direito sobre tais casas e impôsse, aos litigantes, "perpetuum silentium" sobre o assunto ${ }^{44}$.

A vida na clausura não terá sido, contudo, sempre turbulenta como parecem sugerir os documentos citados. Conhecemos exemplos de boas vidas, ou pelo menos de vidas bem sucedidas ao serviço da Igreja, entre os professos de S. Jorge de Coimbra. Neste claustro se criou, numa demonstração, creio, da vitalidade de recomposição disciplinar que ali se alcançou, para a vida religiosa, "in minori officio constitutus", um tal Domingos, sobrinho do prior-mor dessa canónica, D. Martinho Miguéis ${ }^{45}$.

\footnotetext{
${ }^{42}$ TT — Sé de Coimbra, M $^{\circ}$ 15, Doc. 30.

${ }^{43}$ TT - Sé de Coimbra, $2^{\mathrm{a}}$ incorporação, $\mathrm{M}^{\mathrm{o}} 84$, Doc. 3805.

${ }^{44}$ TT - Mosteiro de S. Jorge de Coimbra, M M $^{\mathrm{T}}$, Doc. 12.

${ }^{45}$ D. Martinho Miguéis é prior-mor já em 10 de Junho de 1273. (TT — Mosteiro de S. Jorge de Coimbra, M 6, Doc. 32). D. Timóteo dos Mártires regista-o como prior-mor entre 1273 e 1279. (Op. cit., p. 5).
} 
Este Domingos "fuit assumptus ad episcopalis apicem Elborensis", sendo pois D. Domingos Eanes Jardo, bispo de Évora entre 1285 e 1289. Por intervenção do agora prelado eboracense, o prior-mor da canónica, D. Fernando Gonçalves, com os cónegos, por acordo de 4 de Dezembro de 1286, comprometeram-se a celebrar, por alma desse seu anterior prelado da canónica, uma missa conventual todos os anos, devendo dar-se ao convento, nessa ocasião, “ad suam uictualium refectionem”, 10 libras velhas portuguesas, as quais seriam confiadas ao prior claustral ou, na sua ausência, ao "sacrista" 46 .

Os elogios que, neste compromisso piedoso, são tecidos à memória do velho prior-mor, D. Martinho Miguéis, embora se compreendam pela intencionalidade de lisonja para com a figura do então bispo de Évora, seu sobrinho, não deixam de expressar, ainda assim, o ideal de desempenho que se esperava de um prior-mor de uma canónica regular agostiniana: "laudabilem uitam et conuersationem venerabilis et religiosi patris domni Martini Michaelis quondam prioris nostri et labores quos ipse sostinuit pro bonis ipsius Monasterium nom solum spiritualibus sed etiam temporalibus augmentandis necnon bona multimoda et auxilia que nobis et nostro Monasterio ipsius persone intuitu fecit" $" 47$.

Em 1321, S. Jorge de Coimbra foi taxado em 900 libras, significativamente abaixo de Santa Cruz de Coimbra, com 13700 libras, a mesa prioral, e outras 5500, o convento, mas consideravelmente acima, por exemplo, de outra canónica regrante, não muito distante no espaço geográfico, como S. Pedro de Arganil, estimada em 400 libras ${ }^{48}$.

A dimensão do património de S. Jorge permitia, ainda por todo o século XIV, um confortável nível de vida aos seus professos. Isso é muito claro, por exemplo, em 1334, quando o prior-mor concordava em "que os coonigos e os frades confessos do dicto

\footnotetext{
${ }^{46}$ TT - Mosteiro de Santa Cruz de Coimbra, 2a incorp., Mº 238, Doc. com a cota antiga: “Alm. 60, n” 2, $\mathrm{m}^{\circ} 12$ ".

${ }^{47}$ TT - Mosteiro de Santa Cruz de Coimbra, 2a incorp., M $^{\mathrm{o}} 238$, Doc. com a cota antiga: “Alm. 60, $\mathrm{n}^{\mathrm{o}} 2$, $\mathrm{m}^{\mathrm{o}} 12^{\prime \prime}$.

${ }_{48}$ AMEIDA, Fortunato de - História da Igreja em Portugal. Nova edição preparada por Damião Peres. Vol. IV. Porto-Lisboa: Livraria Civilização, 1971, p. 12-123.
} 
monasterio de cada dia ajam pera seu mantimento tres pãees cada huum coonigo e frade e serem tamanhos que do alqueire da farinha triga peneirada polla ante maao e seendo-lhe a mão posta hûa vez que do alqueire fossem fectos dezeoyto pãaes [...] $e$ cada dia ajam d'aver tres fiaas de vinhos, o vaso da colaçom, e da noa e da presa o qual vinho seer terçado as duas partes de vinho e a hûa d'augua"49.

Em 1368, Afonso Gonçalves, prior de S. Jorge de Coimbra era também o reitor da Universidade, ao tempo instalada nesta cidade ${ }^{50}$. Em 1423, o Infante D. Pedro suplica ao papa a nomeação de Fr. João Verba, dominicano e seu confessor, para o priorado do Mosteiro de S. Jorge, vago pelo falecimento de Álvaro Gonçalves, avaliando-se os seus frutos em 200 libras pequenas de Tours ${ }^{51}$. O ciclo de comendatários deste Mosteiro, testemunhando a cobiça de alguns sobre as suas pingues rendas e o seu vasto património, prolongar-se-á pelo século XVI dentro ${ }^{52}$.

\section{FONTES E BIBLIOGRAFIA}

\section{Fontes manuscritas}

Direcção Geral de Arquivos - Torre do Tombo

Mosteiro de S. Jorge de Coimbra, $\mathrm{M}^{\mathrm{o}}$ 1, Docs. 35 a 37.

Mosteiro de S. Jorge de Coimbra, $\mathrm{M}^{\mathrm{o}}$ 3, Docs. 10, 12 e 15.

Mosteiro de S. Jorge de Coimbra, $\mathrm{M}^{\mathrm{o}}$ 4, Docs. 5, 29 e 30.

Mosteiro de S. Jorge de Coimbra, $\mathrm{M}^{\mathrm{o}}$ 6, Docs. 2, 21 e 32.

\footnotetext{
49 Citado por COELHO, Maria Helena da Cruz - "Apontamentos sobre a comida e a bebida do campesinato coimbrão em tempos medievos". In Homens, Espaços e Poderes. Séculos XI-XVI. I - Notas do viver social. Lisboa: Livros Horizonte, 1990, p. 9-22: 13.

${ }^{50}$ CHARTULARIUM Universitatis Portugalensis (1288-1537), Vol. 1 (1288-1377). Lisboa: Instituto de Alta Cultura, 1966, Docs. 256 e 260, p. 275 e 280.

51 COSTA, António Domingues de Sousa - Monumenta Portugaliae Vaticana. III-2. Súplicas do pontificado de Martinho V (Anos 1-7). [Braga]: Editorial Franciscana, 1982, Doc. 473, p. 487.

52 GOMES, S. A. - “Os cónegos regrantes de Santo Agostinho em tempos de Reforma: 1500-1530”. In Actas do III Congresso Histórico de Guimarães. D. Manuel e a sua época. Vol. II. Guimarães: Câmara Municipal de Guimarães, 2004, p. 255-281: 263-264.
} 
Mosteiro de S. Jorge de Coimbra, M $^{\mathrm{o}}$ 7, Doc. 12.

Mosteiro de Santa Cruz de Coimbra, $2^{\mathrm{a}}$ incorporação, $\mathbf{M}^{\mathbf{0}} 238$, Doc. com a cota antiga: “Alm. 60, no 2, m 12".

Sé de Coimbra, M $^{\text {15 }}$, Doc. 30.

Sé de Coimbra, $2^{\mathrm{a}}$ incorporação, $\mathrm{M}^{\mathrm{o}}$ 84, Doc. 3805.

\section{Fontes impressas}

CHANCELARIA de D. Afonso III. (Ed. VENTURA, Leontina e OLIVEIRA, António Resende de), Livro 1 - Volume 1, Coimbra, Imprensa da Universidade de Coimbra, 2006.

CHARTULARIUM Universitatis Portugalensis (1288-1537), Vol. 1 (1288-1377). Lisboa: Instituto de Alta Cultura, 1966.

COSTA, António Domingues de Sousa - Monumenta Portugaliae Vaticana. III-2. Súplicas do pontificado de Martinho V (Anos 1-7). [Braga]: Editorial Franciscana, 1982.

DOCUMENTOS de D. Sancho I (1174-1211), (Ed. AZEVEDO, Rui de, COSTA, Avelino de Jesus da e PEREIRA, Marcelino Rodrigues). Coimbra: Centro de História da Universidade de Coimbra, 1979.

MÁRTIRES, D. Timóteo dos - "Mosteiro de São Jorge de junto a Coimbra. Sua fundação, união, refformação e huns e outros priores”, O Instituto, No 121 (1959), p. 120.

SANTA MARIA, D. Nicolau de - Chronica da Ordem dos Conegos Regrantes do Patriarcha S. Agostinho. Parte II. Lisboa: Oficina de João da Costa, 1668. 


\section{Estudos}

ALBUQUERQUE, Martim de - A Torre do Tombo e os seus tesouros. Lisboa: Inapa, 1990.

AMEIDA, Fortunato de - História da Igreja em Portugal. Nova edição preparada por Damião Peres. Vol. IV. Porto-Lisboa: Livraria Civilização, 1971.

AMARAL, Luís Carlos - São Salvador de Grijó na segunda metade do Século XIV. Estudo de gestão agrária. Lisboa: Edições Cosmos, 1994.

BAIÃO, António e AZEVEDO, PEDRO DE - O Arquivo da Torre do Tombo, sua história, corpos que o compõem e organização, Lisboa, 1905 [edição facsimilada, Lisboa, ANTT, 1989].

BERTRAND, Paul - Commerce avec dame Pauvreté. Structures et fonctions des couvents mediants à Liège (XIIIe-XIVe s.). Liège: Université de Liège. 2004.

BISSON, Thomas N. - Fiscal accounts of Catalonia under the Early Count-Kings (1151-1213). Vol. 1. Introduction. Berkeley-Los Angeles-London: Univerity of California Press, 1984.

BOISSELLIER, Stephane - Registres fiscaux et administratifs de benefices ecclésiastiques du royaume portugais, XIII-XIVe siècles (edition et présentation). Contribution a l'étude du phenomène administratif, [2009], (no prelo).

IDEM, "Les rapport entre prélèvement fiscal et mécanismes économiques: leurs représentations dans les Cortes au Portugal dans la première moitié du XIVe siècle". In La fiscalità nell'economia europea. Secc. XIII-XVIII. Atti XXXIX Settimana di Studi, (Ed. Simonetta CAVACIOCCHI). Florença, 2008, p. 1083-110.

BOTÃO, Maria de Fátima - “As fontes contabilísticas na retratação de um espaço em movimento”. In Paisagens Rurais e Urbanas - Fontes, Metodologias, Problemáticas. Actas das Primeiras Jornadas. Lisboa: Centro de Estudos Históricos da Universidade Nova de Lisboa, 2005, p. 123-131. 
Um registo de contabilidade medieval do Mosteiro de S. Jorge de Coimbra (1257-1259) - Saul António Gomes

CLANCHY, M. T. - From Memory to Written Record: England, 1066-1307. Oxford: Blackwell, 1993.

COSTA, Avelino de Jesus da - O Bispo D. Pedro e a organização da Diocese de Braga. 2 vols.. $2^{a}$ edição. Braga2000.

COELHO, Maria Helena da Cruz - O Baixo Mondego nos Finais da Idade Média. (Estudo de História Rural). 2 vols. Coimbra: Faculdade de Letras, 1983.

IDEM - “O senhorio crúzio do Alvorge na Centúria de Trezentos”. In Homens, Espaços e Poderes. Séculos XI-XVI. II - O Domínio Senhorial. Lisboa: Livros Horizonte, 1991, p. 31-92.

IDEM - "Apontamentos sobre a comida e a bebida do campesinato coimbrão em tempos medievos”. In Homens, Espaços e Poderes. Séculos XI-XVI. I - Notas do viver social. Lisboa: Livros Horizonte, 1990, p. 9-22.

CUNHA, Maria Cristina de Almeida - A Chancelaria Arquiepiscopal de Braga (10711244). Porto: Faculdade de Letras da Universidade do Porto, 1998.

DINIS, Maria José - O Mosteiro de S. Jorge. Subsídios para a sua história nos séculos XII e XIII, [Dissertação de Licenciatura, policopiada]. Coimbra: Faculdade de Letras da Universidade de Coimbra, 1961.

DUBY, G. - "Le budget de l'abbaye de Cluny entre 1080 et 1155 . Économie domaniale et économie monétaire". In Hommes et structures du moyen âge. Recueil d'articles. Paris-La Haye: École des Hautes Études en Sciences Sociales e Paris \& Mouton Éditeurs, 1984, p. 61-82.

FARELO, Mário - "Bibliografia sobre fiscalidade eclesiástica", divulgado on line em http://www.fcsh.unl.pt/iem/disponibilizar-biblio-iem-htm, 2007. [Consult. 16 Jun. 2010].

FONSECA, Luís Adão da - “As finanças reais no governo do Condestável Pedro de Portugal em Barcelona (1464-1466)". Separata de El Món Urbà a la Corona d'Aragó 
Um registo de contabilidade medieval do Mosteiro de S. Jorge de Coimbra (1257-1259) - Saul António Gomes

del 1137 als Decrets de Nova Planta. XVII Congrés d'Història de la Corona d'Aragó. Barcelona-Lleida, 7-12 de setembre del 2000, p. 1-5.

GOMES, S. A. - "O notariado medieval português. Algumas notas de investigação". Humanitas. Coimbra. Instituto de Estudos Clássicos da Faculdade de Letras da Universidade de Coimbra. LII (2000), p. 241-286

IDEM - "O "Inventário das Escrituras" do Convento de S. Francisco de Santarém de [1411]. Observações breves acerca da praxis arquivística medieval portuguesa". Revista de História da Sociedade e da Cultura. Coimbra. Centro de História da Sociedade e da Cultura da Universidade de Coimbra. 3, (2003 [2004]), p. 263-292.

IDEM - "A Chancelaria do Mosteiro de S. Vicente de Fora de Lisboa nos Séculos XII e XIII: Subsídio para o seu Conhecimento". In Svmmvs Philologvs Necnon Verborum Imperator. Colectânea de Estudos em Homenagem ao Académico de Mérito, Professor Dr. José Pedro Machado no seu $90^{\circ}$ Aniversário. Lisboa: Academia Portuguesa da História, 2004, p. 163-213.

IDEM - "Os cónegos regrantes de Santo Agostinho em tempos de Reforma: 15001530”. In Actas do III Congresso Histórico de Guimarães. D. Manuel e a sua época. Vol. II. Guimarães: Câmara Municipal de Guimarães, 2004, p. 255-281.

IDEM - "Percepções em torno da história do tabelionado medieval português". Revista de História da Sociedade e da Cultura. Coimbra. Centro de História da Sociedade e da Cultura da Universidade de Coimbra. 5 (2005), p. 81-100.

IDEM - “DONATIONES CVSTODIANTVR: DONATIONES SERVENTVR' Da memória e praxis arquivística do Mosteiro de Santa Maria de Alcobaça em tempos medievais". Humanitas. Instituto de Estudos Clássicos da Faculdade de Letras da Universidade de Coimbra. 57 (2005), Coimbra, p. 245-269.

IDEM - In limine conscriptionis. Documentos, chancelaria e cultura no Mosteiro de Santa Cruz de Coimbra. Séculos XII a XIV. Coimbra: Palimage, 2007. 
Um registo de contabilidade medieval do Mosteiro de S. Jorge de Coimbra (1257-1259) - Saul António Gomes

IDEM - “ 'Trado me ipsum...' - Registos medievais de traditio monástica entre os Cónegos Regrantes de Santo Agostinho em Portugal". In Estudos em Homenagem ao Professor Doutor José Marques. Vol. 4. Porto: Faculdade de Letras da Universidade do Porto, 2006, p. 329-348.

IDEM - Um Mosteiro de Cónegos Regrantes em Tempos Medievais: S. Pedro de Folques (Arganil) (no prelo [2008]).

GONÇALVES, Iria - “Custos de montagem de uma exploração agrícola medieval”. In Estudos de História de Portugal. Séculos X-XV. Homenagem a A. H. de Oliveira Marques. Lisboa: Editorial Estampa, 1982, p. 255-270

IDEM - O Património do Mosteiro de Alcobaça. Lisboa: Universidade Nova de Lisboa, 1989.

GOODY, J. - A lógica da escrita e a organização das sociedades. Lisboa: Ed. 70, 1987.

GUYOTJEANNIN, Olivier - Les sources de l'histoire médiévale. Paris: Librairie Générale Française, 1998.

KRUS, Luís - “A Consolidação de Portugal”. In Memória de Portugal. O Milénio Português (Dir. Roberto Carneiro; Coord. Artur Teodoro de Matos). Rio de Mouro: Círculo de Leitores. 2001, p. 107-163, maxime 126-127 e 142-143.

MARQUES, A. H. de Oliveira - “A população portuguesa nos fins do século XIII”. In Ensaios de história medieval portuguesa. $2^{a}$ edição. Lisboa: Ed. Veja. 1980, p. 51-92.

MARQUES, José - "O censual do Cabido de Tui para o arcediagado da terra da Vinha 1321”. In Relações entre Portugal e Castela nos finais da Idade Média. Lisboa: Fund. Calouste Gulbenkian e FCT, 1994, p. 65-104.

MARTIN MARTIN, Luis - "El poblamiento de Portugal según 'Collectoriae' vaticanas del siglo XIV: diócesis de Lisboa y Coimbra". Revista da Faculdade de Letras. História. Porto. Faculdade de Letras da Universidade do Porto., 13, 2 a série, (1996), p. $123-148$ 
Um registo de contabilidade medieval do Mosteiro de S. Jorge de Coimbra (1257-1259) - Saul António Gomes

MARTINS, Armando Alberto - O Mosteiro de Santa Cruz de Coimbra na Idade Média. Lisboa: Centro de História da Universidade de Lisboa, 2003.

MATTOSO, José - A escrita da História. Teoria e métodos. Lisboa: Estampa, 1988

MORUJÃO, Maria do Rosário Barbosa - A Sé de Coimbra: a Instituição e a Chancelaria (1080-1318). Coimbra: Faculdade de Letras da Universidade de Coimbra, 2005.

NOGUEIRA, Bernardo de Sá - Tabelionado e instrumento público em Portugal. Génese e implantação (1212-1279). Lisboa: INCM, 2008.

IDEM - “A organização do padroado régio durante o reinado de D. Dinis. Lista das apresentações (1279-1321)". In Arqueologia do Estado. 1ª Jornadas sobre formas de organização e exercício dos poderes na Europa do Sul. Séculos XIII-XVIII. Comunicações. Vol. 1. Lisboa: Faculdade de Letras da Universidade de Lisboa. 1988, p. 421-445.

POWER, Eileen - "Medieval Monastic Finance". The Economic History Review. Vol. 7, $\mathrm{N}^{\mathrm{o}} 1$ (Nov., 1936). p. 87-92.

RACINET, Philippe - Moines et monastères en Occident au Moyen Âge en hommage à Dom Jacques Dubois. Paris: Ed. Ellipses, 2007.

ROSA, Maria de Lurdes - "Problemáticas históricas e arquivísticas actuais para o estudo dos arquivos de família portugueses (Épocas Medieval e Moderna)”. Revista de História da Sociedade e da Cultura, Coimbra. Centro de História da Sociedade e da Cultura. 9 (2009), p. 9-42.

SANTOS, Maria José Azevedo - "Remarques sur les conditions de conservation des actes et des livres au Portugal (XIIe-XVe siècles). Scriptorium, T. L (1966-2), p. 397406.

SILVA, Carlos Guardado da - O Mosteiro de S. Vicente de Fora. A comunidade regrante e o património rural (Séculos XII-XIII). Lisboa: Ed. Colibri, 2002. 
Um registo de contabilidade medieval do Mosteiro de S. Jorge de Coimbra (1257-1259) - Saul António Gomes

SILVA, Maria João Oliveira e - Scriptores et notatores. A produção documental da Sé do Porto (1113-1247). Porto: Fio da Palavra, 2008.

SNAPE, R. - English monastic finances in the Later Middle Ages. Cambridge, 1926.

SOALHEIRO, João - "Censual da diocese de Coimbra - século XIV (ANTT: MCO, Ordem de Cristo/Convento de Tomar, liv. 264)". Revista de História da Sociedade e da Cultura. Coimbra. Centro de História da Sociedade e da Cultura da Universidade de Coimbra., 6 (2006), p. 51-90.

SOUSA, Bernardo Vasconcelos e (Dir.) - Ordens Religiosas em Portugal das origens a Trento. Guia Histórico. Lisboa: Livros Horizonte, 2006.

VAUCHEZ, A. E CABY, Cécile (Dir.) - L'Histoire des moines, chanoines et religieux au Moyen Âge. Guide de recherche et documents. Turnhout: Brepols, 2003.

VILAR, M. Hermínia - "Do arquivo ao registo: o percurso de uma memória no reinado de Afonso II". Penélope. Revista de História e Ciências Sociais. Lisboa. No 30/31 (2007), p. 19-50.

IDEM - D. Afonso II. Um rei sem tempo. Rio de Mouro: Círculo de Leitores. 2005.

\section{Documento}

[1258-1259] — Registo do deve e do haver do Mosteiro de S. Jorge de Coimbra relativamente aos anos de 1257 e 1259 .

TT — Sé de Coimbra, Maço 15, Doc. 30.

Obs.: Este documento foi integrado no fundo da Sé de Coimbra, $1^{\text {a }}$ incorporação, na Torre do Tombo. É originário, contudo, do Mosteiro de S. Jorge de Coimbra, muito embora o seu conteúdo não explicite clara nem assertivamente tal proveniência. No verso do pergaminho, um lanço em escrita gótica cursiva, ducentista, regista a 
informação: "super facto sancti Georgii”. Mão já do século XVIII averbou, também nesse lado do documento: " $\mathrm{N}^{0}$ 53. Rotulo do que ao Mosteiro de S. Jorge herão obrigados a pagar certas pessoas. Innutil.” O teor do documento respeita a um mosteiro de Coimbra, nunca explicitamente nomeado, como se referiu, salvo nestes averbamentos "arquivísticos", mas que, pela análise crítica das referências, não pode deixar de ser uma canónica, desde logo pela insistência nos bens e direitos da mesa do "prior", o que aponta categoricamente para um instituto de cónegos regrantes. As referências às propriedades de Penela, de Façalamim ou de S. Vicente da Beira, como ainda à ovença de Santarém, entre outras, são indicadores seguros de que o assunto respeita aos cónegos de S. Jorge e não a Santa Cruz de Coimbra.

De Era $\cdot M^{a}$. CC ${ }^{a}$ LX $(X X X)^{a}$. V ${ }^{a}$. Accepit prior de infirmitorio .iij. modios ordei et unum sarracenum.

Item de Era , $\mathrm{M}^{\mathrm{a}}$. CC $\mathrm{CC}^{\mathrm{a}}$ $\mathrm{LX}(\mathrm{XXX})^{\mathrm{a}}$. $\mathrm{VI}^{\mathrm{a}}$. Accepit de infirmitorio .viij. modios tritici maurici et milium et ordeum et ualebat tunc temporis alquerium tritici .iiij. solidos et non dedit ipse nisi xxvij. libris. Dominico Munionis pro tritico supradicto ordeo atque milio.

Item de hereditate Sancti Simeonis de Penellola quam uendidit recepit Lxxx. libris.

Item de Lorbano $\mathrm{X}(\mathrm{XXX})$ libris de quibus debet vestiaria et correaria duas partes habere.

Item de Domno Gunsaluo nepote Domni Sebastiani .L. morabitinis de quibus debet vestiaria et correaria duas partes habere.

Item de quodam homine de Tentugal; xij. libris de quibus debet vestiaria e correaria duas partes habere.

Item de Petro Manso de Fazalamil; xiij. modios tritici maurici quod ualebat tempore illo; alquerium .iiij. solidos de quibus debet vestiaria et correaria duas partes habere. 
Item de Picarrel ${ }^{53}$.xxij. libris de pannis ${ }^{54}$ de quibus debet vestiaria et correaria duas partes habere.

Item de Vincentio Petri Sarrano; xiij. libris et alias tres pro mensa sua facienda, de quibus debet vestiaria et correaria duas partes habere.

Item de Vincentio ouelario .Lxxx. oues et unum asinum de quibus debet vestiaria et correaria duas partes habere.

Item de Domno Petro fratre Domni Sebastiani; viij. uacas et unum bouem et . $\mathrm{x}(\mathrm{xxx})$. oues <et plus>. preter mensa quam promisit pro eo facere; et non fecit. de quibus debet vestiaria et correaria duas partes habere.

Item de Durando ouelario .xiij. libris et Lx oues, preter mensam quam promisit pro eo facere et non fecit. de quibus debet vestiaria et correaria duas partes habere.

Item de quandam Domna Dona recepit .C. libris de quibus debet vestiaria et correaria duas partes habere.

Item de Domino Rege .x. modios milii quos dedit ipse Rex pro pitancia fratribus et nihil inde habuerunt.

De vinea correarie accepit totum uinum in Era $\cdot \mathrm{M}^{\mathrm{a}} \cdot \mathrm{CC}^{\mathrm{a}} \cdot \mathrm{LX}(\mathrm{XXX})^{\mathrm{a}}$. VI ${ }^{\mathrm{a}}$. quod laboraret supradictam uineam bene et non cauauit eam nisi semel et etiam male quando erat <iam> cum foliis suis.

Item de mauro Mafomede recepit .Lvij. libris.

Item de quibusdam oliuetis; que tenet Domnus Benedictus fibularius recepit .v. libris pro brocagine et oliueta erant de correaria.

Item de duobus annis de capitulo tenetur capitulo dare .vj. libris et alias sex amisimus propter eum scilicet de Ameal .ij. de Couelliana .ij. libris. de Sancto Vincentio de ultra serram .ij. libris.

Item de uno anno de Sanctarene de pitancia .xxx. libris et amplius de pane que accepit de pitancia.

Item de Petro Gunsalui de Paliom habuit .viij. capita uacarum per magnas et paruas et .x. capras et tres asinos et unum bouem bonum zorome et sagiam, de quibus debet vestiaria et correaria duas partes habere.

Item de Albarriol qui est de pitancia dedit eum Fernando Martini de Penella unde consueuimus habere .iij. libris annuatim et amplius.

\footnotetext{
${ }^{53}$ Seguem-se palavras riscadas e rasuradas "per manus et per ..." (?).

${ }^{54}$ Seguem-se palavras riscadas e rasuradas: “... xxx panis; xxij libris".
} 
Item de almunia de correaria habuit .vij. libris de ferragine. Et de molendinis quidam die .iiij. libris et dimidiam.

De villa Sancti Vincentii de ultra serram de qua consueuimus habere .CC. libris annuatim nichil inde habuimus scilicet de Era $\cdot M^{a}$. CC. LX $(X X X)^{a}$. V ${ }^{a}$ et de Era $\cdot M^{a}$. $C^{a} \cdot \operatorname{LX}(X X X)^{a}$. VI $I^{a}$ et de Era $\cdot M^{a} \cdot C^{a} \cdot \operatorname{LX}(X X X)^{a}$. VII ${ }^{a}$.

Item de ospitali habuit de duobus annis lanam de .CCC. ouibus et in eodem ospitali habebant .xxiiij. almocelas quando uenet prior et modo non habent nisi iiij ${ }^{\text {or }}$ uel quinque et hoc; ocasione prioris.

Capitulum duo anni sunt elapsi quod non fuit facturum siue celebratum.

De Portu Alacri habet unam bonam uineam et unam apotecam quam dedit Domnus Suerius de Canrantonia Monasterio nostro et nobis pro anima sua de quibus debet habere correaria et vestiaria duas partes et sic debent habere de omnibus legatis nostro Monasterio supradictis.

In Couelliana habet quasdam bonas casas similiter quas legauerunt nobis et nihil habent inde correaria nec vestiaria, et preter hoc quasdam uineas et alias possessiones de quibus nihil habemus.

In Arganil prope Guardiam habemus ibi quedam casalia unde recepit prior annuatim; ij. libris.

In Celorico habemus iiij ${ }^{\text {or }}$ casalia que similiter legata fuerunt nobis et Monasterio nostro; et nihil inde habemus iam duo anni sunt elapsi.

De Paacios ubi habemus tria casalia unde habuit ipse annuatim .iij. libris et amplius ualent nihil inde habemus.

Item de una uinea de pitancia quam tenet Magister Suerius unde debet habere pitancia annuatim .ij. libris nihil habet inde ocasione prioris.

Dedit tres pecias terre prior Petro Saluati mercatori duas quas habemus in Campo prope Montem Maiorem et unam quam habemus in Barrio prope Monte Maiorem et iste pecie spectant ad correariam et vestiariam et ad priorem.

De Riuulo Molendinorum de prope uilla Sancti Vincentii de ultra serram; habuit prior .v. modios panis et hoc fuit de Era $\cdot \mathrm{M}^{\mathrm{a}}$. CC ${ }^{\mathrm{a}} \cdot \mathrm{LX}(\mathrm{XXX})^{\mathrm{a}}$. VI ${ }^{\mathrm{a}}$. unde debet habere vestiaria medietatem.

Item recepit prior de tercia Johannis Suerii qui habitabat Ameal in loco qui dicitur Maruam; ualorem .xx ${ }^{\mathrm{ti}}$. librarum. 
Dedit prior.$v^{\mathrm{e}}$ casalia Petro Saluati que sunt in Ameal pro quatuor annis pro .C. libris que bene ualent .CC. libris.

Recepit prior de pannis quos uendidt Vincencio Sarrano .xij. libris.

Accepit tempore quo erat Dominicus Munionis correarius .vij. arietes de correaria.

De anno isto proximo preterito queratis ab infirmario quid prior accepit inde uel quid sibi debet dare et ita faciatis de correaria.

Item dedit prior unam bestiam de vestiaria Johanni Pelagii de Couelliana et alias duas bestias dedit Pelagio Petri dicto Lanyoso.

Accepit prior stramenta et coopertora de .vij. fratribus qui sunt mortui.

II Hec sunt debita que debet Monasterium dare tantum de pane istius anni et anni preteriti proximi.

Petro Manso de Fazalamil .vj. modios tritici.

Martino Pelagii canonico Colimbriensis .ij. modios tritici et .ij. modios milii.

Petro Saluati mercatori .j. modium tritici.

Domino Episcopo Colimbriensis .ij. modios milii et .ij. quartarios tritici.

Martino Pelagii carpentario de parrochia Sancti Bartholamei .j. modium milii.

Martino Munionis mercatori .vj. quartarios tritici.

\section{COMO CITAR ESTE ARTIGO}

\section{Referência electrónica:}

GOMES, Saúl António - "Um registo de contabilidade medieval do Mosteiro de

S. Jorge de Coimbra (1257-1259)". Medievalista [Em linha]. No 10, (Julho de 2011).

[Consultado dd.mm.aaaa]. Disponível em

http://www2.fcsh.unl.pt/iem/medievalista/MEDIEVALISTA10〈gomes1003.html.

ISSN 1646-740X. 
Um registo de contabilidade medieval do Mosteiro de S. Jorge de Coimbra (1257-1259) - Saul António Gomes

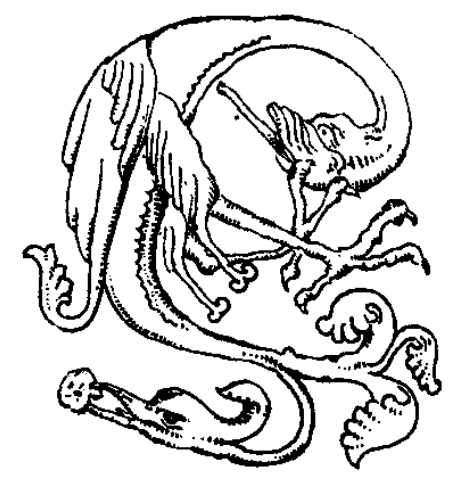

Medievalísta online № 10| Julho - Dezembro 2011 (C) IEM - Instituto de Estudos Medievais 29 www2.fcsh.unl.pt/iem/medievalista 